\title{
Percepção das mulheres privadas de liberdade sobre a assistência à saúde recebida no pré-natal, parto e puerpério: revisão integrativa
}

\author{
Perception of women deprived of liberty about the health care received in prenatal care, \\ childbirth and puerperium: an integrative review
}
Percepción de las mujeres privadas de libertad sobre la atención de salud recibida en el prenatal, parto y puerperio: una revisión integradora

Laura Martins Hipólito Fortunato ${ }^{1 *}$, Letícia Gomes Meira ${ }^{1}$, Carla de Paula Silveira ${ }^{1}$, Érika Marina Rabelo', Isabela Mie Takeshita'.

\section{RESUMO}

Objetivo: Descrever, do ponto de vista das mulheres privadas de liberdade, como ocorre a assistência à saúde durante a gestação, parto e puerpério. Métodos: Pesquisa de revisão integrativa da literatura, com análise sistemática dos dados tendo como foco, o seguinte problema de pesquisa: "Qual a percepção da mulher privada de liberdade sobre a assistência à saúde recebida no pré-natal, parto e puerpério?". Os dados utilizados no presente estudo foram obtidos na Biblioteca Virtual em Saúde (BVS). Os descritores utilizados foram "Gestação", "Maternidade", "Preso", "Prisão". Resultados: Os estudos encontrados destacam a complexidade de vivenciar o processo gravídico-puerperal em situação de privação de liberdade. As percepções das mulheres revelam fragilidades na assistência materno-infantil nas penitenciárias. As relações são desumanas e podem ser evidenciadas pela fragilidade do pré-natal, ausência de acompanhante durante o parto e puerpério sem assistência. Considerações finais: A maioria das instituições necessitam de ajustes e adaptações para cumprir o que é preconizado pela legislação brasileira. Dessa forma, os direitos das mulheres e filhos são ignorados e reforçam a marginalidade dessa população. Alguns aspectos encontrados nos resultados não puderam ser discutidos com profundidade, devido à falta de literatura específica.

Palavras-chave: Gravidez, Maternidade, Presos, Prisões, Atenção à saúde.

\section{ABSTRACT}

Objective: To describe, from the point of view of women deprived of liberty, how health care occurs during pregnancy, childbirth and the puerperium. Methods: Integrative literature review research, with systematic data analysis focusing on the following research problem: "What is the perception of women deprived of freedom about the health care received in prenatal care, childbirth and puerperium?". The data used in this study were obtained from the Virtual Health Library (VHL). The descriptors used were "Pregnancy", "Maternity", "Prisoner", "Prison". Results: The studies found highlight the complexity of experiencing the pregnancy-puerperal process in a situation of deprivation of freedom. Women's perceptions reveal weaknesses in maternal and child care in prisons. The relationships are inhumane and can be evidenced by the fragility of prenatal care, the absence of a companion during childbirth and the postpartum period without assistance. Final considerations: Most institutions need adjustments and adaptations to comply with what is recommended by Brazilian legislation. In this way, the rights of women and children are ignored and reinforce the marginality of this population. Some aspects found in the results could not be discussed in depth, due to the lack of specific literature.

Keywords: Pregnancy, Parenting, Prisoners, Prisons, Delivery of health care.

\section{RESUMEN}

Objetivo: Describir, desde el punto de vista de las mujeres privadas de libertad, cómo ocurre la atención de la salud durante el embarazo, el parto y el puerperio. Métodos: Investigación de revisión bibliográfica integradora, con análisis sistemático de datos centrado en el siguiente problema de investigación: "¿Cuál es la percepción de las mujeres privadas de libertad sobre la atención de salud recibida en el prenatal, parto y puerperio?". Los datos utilizados en este estudio se obtuvieron de la Biblioteca Virtual en Salud (BVS). Los descriptores utilizados fueron "Embarazo", "Maternidad", "Prisionera", "Prisión". Resultados: Los estudios encontrados destacan la complejidad de vivir el proceso embarazopuerperal en una situación de privación de libertad. Las percepciones de las mujeres revelan debilidades en la atención maternoinfantil en las cárceles. Las relaciones son inhumanas y se puede evidenciar por la fragilidad de la atención prenatal, la ausencia de un acompañante durante el parto y el puerperio sin asistencia. Consideraciones finales: La mayoría de las instituciones necesitan ajustes y adaptaciones para cumplir con lo recomendado por la legislación brasileña. De esta forma, se ignoran los derechos de las mujeres y los niños y se refuerza la marginalidad de esta población. Algunos aspectos encontrados en los resultados no pudieron ser discutidos en profundidad, debido a la falta de literatura específica.

Palabras clave: Embarazo, Responsabilidad parental, Prisioneros, Prisiones, Atención a la salud.

${ }^{1}$ Faculdade Ciências Médicas de Minas Gerais (FCMMG), Belo Horizonte - MG. *E-mail: lauramartinsh@hotmail.com 


\section{INTRODUÇÃO}

O ciclo gravídico-puerperal desdobra-se em pré-natal, parto e puerpério e os cuidados nestas etapas reduzem a morbimortalidade materno-infantil. Durante o pré-natal, a gestante é acompanhada em consultas por profissionais capacitados para detectar e intervir nas situações de risco. O parto demanda assistência especializada (BRASIL, 2013). O puerpério, período de 6-8 semanas após o parto, divide-se entre imediato, mediato e tardio, demanda consultas para o binômio, abordagem de complicações pós-cirúrgicas, amamentação, cuidados com o bebê e planejamento reprodutivo (MAIA JS, et al., 2021).

Dados do Sistema de Informação do Departamento Penitenciário Nacional (SISDEPEN) revelam que no primeiro semestre de 2020 havia 37,16 mil mulheres privadas de liberdade (SISDEPEN, 2020). O Conselho Nacional de Justiça (CNJ) em maio de 2021 divulgou 125 gestantes e 80 lactantes (CNJ, 2021).

A experiência da concepção, gestação e cuidado ao novo ser é permeada por sentimentos e expectativas que diferem entre as gestantes. A maternidade, evento único e que modifica a vida da mulher, perpassa aspectos físicos, hormonais, emocionais e sociais, uma vez que existem expectativas voltadas para a construção do binômio mãe-filho e do futuro dessa relação (FRANÇA AMB e SILVA JMO, 2015).

O Sistema Único de Saúde (SUS) fundamenta-se nos princípios da universalidade, equidade e integralidade. A população carcerária se insere como SUS-dependente e o cuidado garantido pelo Plano Nacional de Saúde no Sistema Penitenciário, na Portaria Interministerial de ㄲ⒈777 de 09/09/2003, agrega os Ministérios da Saúde e da Justiça (CNJ, 2018). Este Plano estabelece diretrizes relacionadas à prevenção, diagnóstico e assistência à pessoa privada de liberdade, com ênfase na qualificação dos serviços prestados à essa população, em especial pelos profissionais da saúde e agentes penitenciários (MINISTÉRIO DA SAÚDE, 2004).

De acordo com o CNJ, somente 48 das 1.420 unidades prisionais brasileiras dispõem de cela adequada para gestantes. O estudo realizado pelo Sistema Integrado de Informações Penitenciárias em 2014, divulgado pelo mesmo Conselho, apontou a existência de 103 unidades destinadas especificamente para mulheres (7\%), enquanto $1.070(75 \%)$ são masculinas e $239(17 \%)$ são mistas, sendo notável que o sistema prisional feminino não está adaptado às necessidades da mulher (VENTURA $M$, et al., 2015).

Equipes do CNJ que percorreram 24 presídios brasileiros em 2018 apontaram desafios e discrepâncias entre as unidades prisionais. Em comum, péssimas condições de: estrutura física, atendimento médico, condições de higiene, alimentação, além de superlotação. As mulheres estão mais expostas a doenças físicas, mentais e quando grávida, à falta de assistência adequada que influenciará no desenvolvimento e resultado da gestação (ARAÚJO ANV, et al., 2014; CNJ, 2018).

Algumas unidades prisionais femininas possuem espaço adaptado para gestantes, lactantes e seus filhos, como o Centro de Referência à Gestante Privada de Liberdade, localizado em Vespasiano, região metropolitana de Belo Horizonte, Minas Gerais. São 57 mulheres, 23 gestantes e 34 lactantes que convivem com seus filhos até um ano de idade (CNJ, 2018).

Esse diferencial permite o aumento do vínculo entre mãe e filho. Quando a criança completa um ano de vida, cerca de $80 \%$ são encaminhadas aos parentes, garantindo a sua permanência na família. As demais são encaminhadas para abrigos. As crianças que permanecem com as mães no presídio têm o direito de atendimento pediátrico, porém há falta de disponibilidade desses profissionais (CNJ, 2018).

O ambiente prisional oferece riscos para a saúde física e mental da mãe e criança. Há escassez de recursos para atender necessidades básicas de saúde, como condições estruturais, alimentação e dificuldade de acesso aos cuidados de saúde, os quais revelam uma realidade que coloca em risco a segurança do binômio (FOCHI MCS, et al., 2014). Dessa forma, o objetivo desse trabalho foi descrever, do ponto de vista das mulheres privadas de liberdade, como ocorre a assistência à saúde durante a gestação, parto e puerpério.

\section{MÉTODOS}

Revisão integrativa da literatura com análise sistemática dos dados que trouxessem conclusões sobre o seguinte problema de pesquisa: "Qual a percepção da mulher privada de liberdade sobre a assistência à saúde recebida no pré-natal, parto e puerpério?". 
Os dados utilizados foram obtidos na Biblioteca Virtual em Saúde (BVS) a partir dos Descritores em Ciências da Saúde (DeCS): "Gravidez", "Maternidade", "Presos", "Prisões", "Atenção à Saúde".

Os artigos foram selecionados a partir da leitura de títulos e resumos, sendo excluídos aqueles que não responderam à pergunta. Foram critérios de inclusão: textos disponíveis na íntegra, idioma português, publicados nos últimos dez anos. Houve foco na realidade brasileira e como a literatura que responde à pergunta de pesquisa se revelou escassa, ampliou-se o período pesquisado. Como critérios de exclusão: artigos duplicados, não disponíveis na íntegra gratuitamente, fora do recorte temporal e que não tivessem relação com a pergunta de pesquisa.

Após os cruzamentos dos descritores foram identificados 619 estudos. Aplicando os critérios de inclusão e exclusão, 35 artigos foram selecionados. Após leitura na integra, 15 artigos apresentaram relação com a pergunta. A Figura 1 revela as etapas do processo.

Figura 1 - Fluxograma do processo de seleção de artigos.

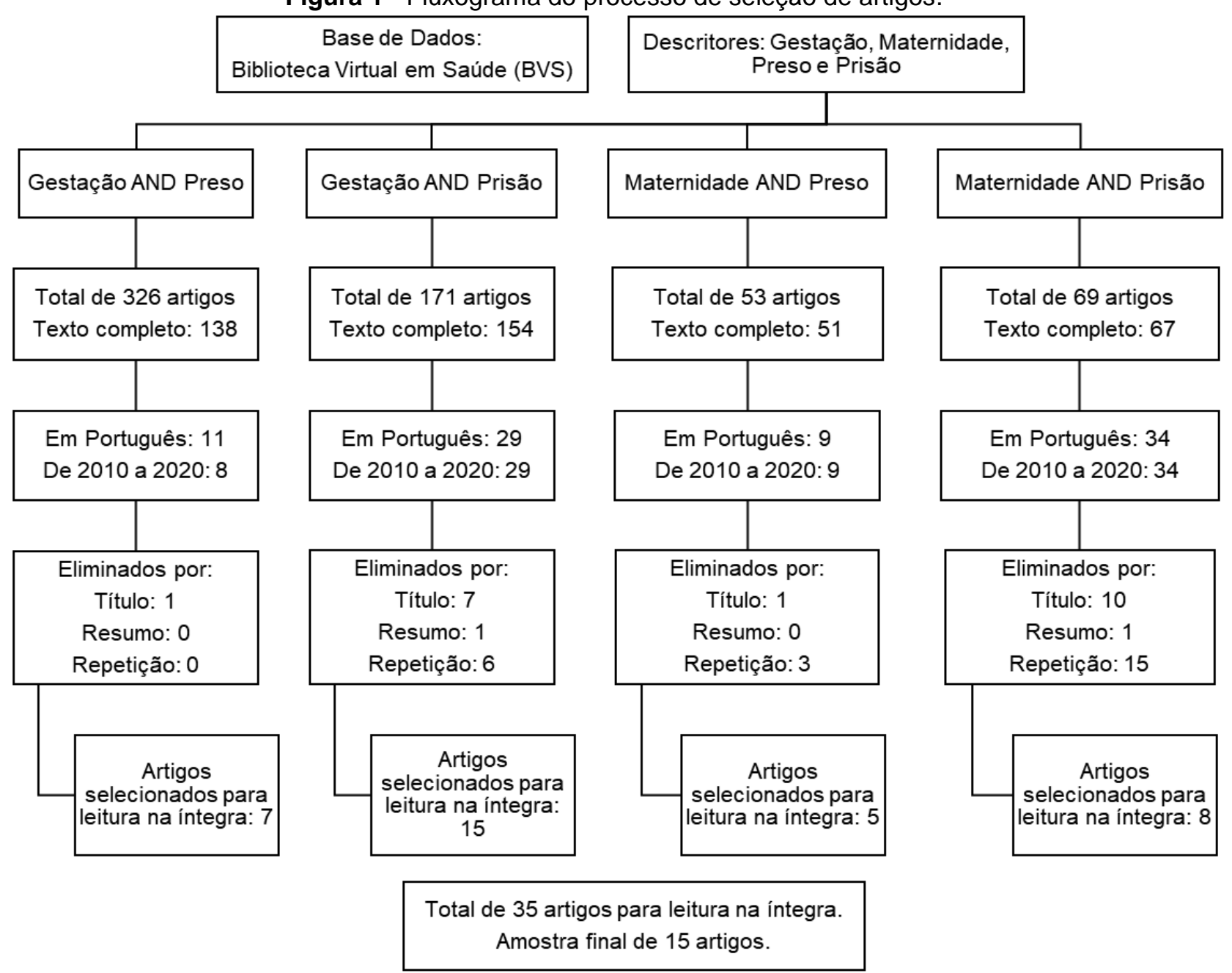

Fonte: Fortunato LMH, et al., 2021.

\section{RESULTADOS E DISCUSSÃO}

No Quadro 1, são apresentados 15 artigos selecionados na amostra final, as informações descritas são caracterizadas por meio de: título, autores (ano), objetivo, metodologia e nível de evidência. Dos artigos encontrados nesta revisão integrativa 11 abordam estudos qualitativos, com entrevistas estruturadas e coleta de dados com as gestantes e lactantes do sistema prisional brasileiro; 3 artigos são revisões integrativas acerca do assunto e um estudo é resultado de um censo institucional nacional. Os artigos foram lidos na íntegra, revisados e classificados conforme a sua descrição e apresentados no (Quadro 1). 
Quadro 1 - Descrição da amostra.

\begin{tabular}{|c|c|c|c|c|}
\hline Título & Autores (Ano) & Objetivo & Metodologia & $\begin{array}{l}\text { Nível de } \\
\text { Evidência }\end{array}$ \\
\hline $\begin{array}{c}\text { Ausência de Assistência à Gestante } \\
\text { em Situação de Cárcere } \\
\text { Penitenciário }\end{array}$ & $\begin{array}{l}\text { GALVÃO MCB e } \\
\text { DAVIM RMB (2013) }\end{array}$ & $\begin{array}{l}\text { Descrever a experiência vivenciada por mulheres } \\
\text { grávidas em sistema penitenciário }\end{array}$ & Pesquisa descritiva qualitativa & 4 \\
\hline $\begin{array}{l}\text { Gestação e Puerpério no Cárcere: } \\
\text { Estudo Descritivo da Atenção à } \\
\text { Saúde }\end{array}$ & $\begin{array}{l}\text { PÍCOLI RP, et al. } \\
\qquad(2014)\end{array}$ & $\begin{array}{c}\text { Descrever as características sociodemográficas, a } \\
\text { história penal e a assistência ao pré-natal e puerpério } \\
\text { de mulheres privadas de liberdade }\end{array}$ & $\begin{array}{l}\text { Estudo descritivo transversal, de } \\
\text { caráter observacional }\end{array}$ & 4 \\
\hline $\begin{array}{l}\text { Mães do cárcere vivências de } \\
\text { gestantes frente à assistência no } \\
\text { pré-natal }\end{array}$ & $\begin{array}{l}\text { SANTANA AT, et al. } \\
\qquad(2016)\end{array}$ & $\begin{array}{c}\text { Compreender as vivências das mulheres frente à } \\
\text { gestação, maternidade e assistência no pré-natal em } \\
\text { cárcere }\end{array}$ & $\begin{array}{l}\text { Pesquisa exploratória descritiva com } \\
\text { delineamento qualitativo. Entrevista } \\
\text { com } 10 \text { gestantes e observação } \\
\text { participante de consultas }\end{array}$ & 4 \\
\hline $\begin{array}{c}\text { Maternidade Atrás Das Grades } \\
\text { Particularidades Do Binômio Mãe E } \\
\text { Filho }\end{array}$ & $\begin{array}{l}\text { MATÃO MEL, et al. } \\
\qquad(2016)\end{array}$ & $\begin{array}{c}\text { Conhecer as particularidades acerca da relação mãe- } \\
\text { filho no ambiente carcerário, na perspectiva de } \\
\text { mulheres em privação de liberdade e de funcionários } \\
\text { do sistema prisional }\end{array}$ & $\begin{array}{l}\text { Pesquisa de campo, descritiva, com } \\
\text { abordagem qualitativa. Entrevista } \\
\text { aberta com presidiárias puérperas e } \\
\text { funcionárias da penitenciária }\end{array}$ & 4 \\
\hline $\begin{array}{l}\text { Nascer na prisão gestação e parto } \\
\text { atrás das grades no Brasil }\end{array}$ & $\begin{array}{l}\text { LEAL MC, et al. } \\
\qquad(2016)\end{array}$ & $\begin{array}{c}\text { Apresentar as características sociodemográficas de } \\
\text { mães vivendo com seus filhos nas prisões, as } \\
\text { condições e as práticas relacionadas à atenção à } \\
\text { gestação e ao parto durante o encarceramento, e a } \\
\text { avaliação feita por elas sobre o atendimento recebido } \\
\text { nas prisões e nas maternidades durante a gravidez e o } \\
\text { parto }\end{array}$ & $\begin{array}{l}\text { Censo de base institucional. Entrevis- } \\
\text { tas estruturadas com } 495 \text { gestantes e } \\
\text { mães, coleta de dados do prontuário, } \\
\text { entrevista com gestores e fotografias } \\
\text { dos cartões de pré-natal e da } \\
\text { caderneta de saúde da criança }\end{array}$ & 4 \\
\hline $\begin{array}{l}\text { Trajetórias de mulheres privadas de } \\
\text { liberdade práticas de cuidado no } \\
\text { reconhecimento do direito à saúde } \\
\text { no Centro de Referência de } \\
\text { Gestantes de Minas Gerais }\end{array}$ & $\begin{array}{l}\text { LOPES TC e } \\
\text { PINHEIRO R (2016) }\end{array}$ & $\begin{array}{l}\text { Analisar a trajetória de cuidado de mulheres de um } \\
\text { Centro de Referência a Gestantes Privadas de } \\
\text { Liberdade (CRGPL), no que concerne às práticas dos } \\
\text { trabalhadores no reconhecimento do direito à saúde e } \\
\text { integralidade do cuidado }\end{array}$ & $\begin{array}{l}\text { Estudo qualitativo. Entrevistas com } \\
\text { mulheres, agentes penitenciárias, } \\
\text { diretores e profissionais de saúde do } \\
\text { CRGPL e do Hospital Sofia Feldman }\end{array}$ & 4 \\
\hline $\begin{array}{l}\text { Percepção de presidiárias sobre a } \\
\text { assistência à saúde materna em uma } \\
\text { penitenciária feminina }\end{array}$ & $\begin{array}{l}\text { FERREIRA LS, et al. } \\
\qquad(2017)\end{array}$ & $\begin{array}{c}\text { Analisar e descrever a percepção de presidiárias } \\
\text { sobre a assistência à saúde materna em uma } \\
\text { penitenciária feminina }\end{array}$ & $\begin{array}{l}\text { Estudo descritivo e exploratório de } \\
\text { abordagem qualitativa. Entrevista } \\
\text { semiestruturada com } 14 \text { presidiárias }\end{array}$ & 4 \\
\hline
\end{tabular}




\begin{tabular}{|c|c|c|c|c|}
\hline Título & Autores (Ano) & Objetivo & Metodologia & $\begin{array}{l}\text { Nível de } \\
\text { Evidência }\end{array}$ \\
\hline $\begin{array}{l}\text { Vivências de gestantes em situação } \\
\text { de prisão }\end{array}$ & $\begin{array}{l}\text { FOCHI MCS, et al. } \\
\qquad(2017)\end{array}$ & $\begin{array}{c}\text { Conhecer as vivências de mulheres grávidas em } \\
\text { situação prisional }\end{array}$ & $\begin{array}{l}\text { Estudo qualitativo e descritivo } \\
\text { realizado em uma penitenciária } \\
\text { feminina do Estado de São } \\
\text { Paulo/Brasil, com } 14 \text { gestantes }\end{array}$ & 4 \\
\hline $\begin{array}{l}\text { Mulheres nas prisões brasileiras } \\
\text { tensões entre a ordem disciplinar } \\
\text { punitiva e as prescrições da } \\
\text { maternidade }\end{array}$ & $\begin{array}{l}\text { DIUANA V, et al. } \\
\qquad(2017)\end{array}$ & $\begin{array}{c}\text { Analisar a interseção das normas de gênero e das } \\
\text { relações disciplinares identificadas na prisão, quando } \\
\text { da experiência da maternidade, identificando } \\
\text { controvérsias no plano dos valores e das relações de } \\
\text { poder que as sustentam }\end{array}$ & $\begin{array}{l}\text { Estudo qualitativo. Entrevistas em } \\
\text { quatro estados brasileiros, } 22 \\
\text { mulheres, gestantes e mães com filhos } \\
\text { na prisão e } 19 \text { profissionais do cárcere }\end{array}$ & 4 \\
\hline $\begin{array}{l}\text { O enfermeiro na atenção pré-natal às } \\
\text { mulheres em sistema carcerário }\end{array}$ & $\begin{array}{l}\text { FÉLIX RS, et al. } \\
\qquad(2017)\end{array}$ & $\begin{array}{l}\text { Descrever a atuação do enfermeiro na atenção pré- } \\
\text { natal com mulheres em sistema carcerário; identificar } \\
\text { dificuldades dos enfermeiros na atenção pré-natal às } \\
\text { encarceradas }\end{array}$ & $\begin{array}{l}\text { Revisão integrativa de artigos } \\
\text { científicos publicados entre } 2006 \text { a } \\
2014 \text { com } 18 \text { artigos }\end{array}$ & 4 \\
\hline $\begin{array}{l}\text { Representações de mulheres } \\
\text { encarceradas sobre gestar na prisão }\end{array}$ & $\begin{array}{l}\text { MATOS KKC, et al. } \\
(2018)\end{array}$ & $\begin{array}{c}\text { Compreender as representações sociais de gestantes } \\
\text { e puérperas encarceradas sobre o gestar enquanto } \\
\text { vivendo em Colônias Penais }\end{array}$ & $\begin{array}{l}\text { Estudo qualitativo por meio de } \\
\text { entrevistas com } 19 \text { mulheres } \\
\text { encarceradas }\end{array}$ & 4 \\
\hline $\begin{array}{l}\text { Maternidade em regime prisional } \\
\text { desfechos maternos e neonatais }\end{array}$ & $\begin{array}{l}\text { ANDRADE ABCA e } \\
\text { GONÇALVES MJF } \\
(2018)\end{array}$ & $\begin{array}{l}\text { Descrever os desfechos, identificados na literatura, da } \\
\text { gestação, parto e puerpério em mulheres privadas de } \\
\text { liberdade }\end{array}$ & $\begin{array}{l}\text { Revisão integrativa de artigos } \\
\text { científicos publicados entre } 2007 \text { a } \\
2017 \text { com } 12 \text { artigos }\end{array}$ & 4 \\
\hline $\begin{array}{l}\text { Reflexões sobre a Assistência em } \\
\text { Enfermagem à Mulher Encarcerada: } \\
\text { Um Estudo de Revisão Integrativa }\end{array}$ & $\begin{array}{l}\text { SOUZA GC, et al. } \\
\qquad(2018)\end{array}$ & $\begin{array}{l}\text { Analisar na literatura as ações de Educação e } \\
\text { Promoção à Saúde de mulheres privadas de } \\
\text { liberdade, com ênfase na fase reprodutiva, nos } \\
\text { períodos de pré-natal, parto e puerpério, no sistema } \\
\text { prisional }\end{array}$ & Revisão integrativa da literatura & 4 \\
\hline $\begin{array}{l}\text { Filhos do cárcere: representações } \\
\text { sociais de mulheres sobre parir na } \\
\text { prisão }\end{array}$ & $\begin{array}{l}\text { MATOS KKC, et al. } \\
(2019)\end{array}$ & $\begin{array}{c}\text { Analisar as Representações Sociais de gestantes e } \\
\text { puérperas encarceradas sobre parir enquanto vivendo } \\
\text { em Colônias Penais }\end{array}$ & $\begin{array}{l}\text { Estudo descritivo-exploratório de } \\
\text { abordagem qualitativa }\end{array}$ & 4 \\
\hline $\begin{array}{l}\text { Mulheres em privação de liberdade } \\
\text { narrativas de des(assistência) } \\
\text { obstétrica }\end{array}$ & $\begin{array}{l}\text { SILVA JB, et al. } \\
(2020)\end{array}$ & $\begin{array}{l}\text { Revelar narrativas de mulheres privadas de liberdade } \\
\text { acerca da assistência obstétrica ofertada durante a } \\
\text { vivência do ciclo gravídico-puerperal }\end{array}$ & $\begin{array}{l}\text { Estudo qualitativo. Entrevista com seis } \\
\text { mulheres no ciclo gravídico-puerperal } \\
\text { em instituição prisional do Nordeste }\end{array}$ & 4 \\
\hline
\end{tabular}

Fonte: Fortunato LMH, et al., 2021. 
As etapas metodológicas seguidas destacaram quatro categorias: Pré-natal da mulher privada de liberdade; O parto e puerpério da mulher privada de liberdade; Formação de vínculo da mulher privada de liberdade com seu filho no ambiente prisional e Mulheres no sistema prisional: relações com a família e os profissionais.

\section{Pré-natal da mulher privada de liberdade}

As gestantes relatam experiências negativas sobre o pré-natal como ausência de orientações referentes à gestação, parto e puerpério, atraso no diagnóstico gestacional, que geram início tardio das consultas e transferência para celas especiais destinadas a gestantes, puérperas e recém-nascidos (LOPES TC e PINHEIRO R, 2016; SILVA JB, et al., 2020). Experiências positivas são relatadas por uma pequena parcela das mulheres que se sentiram acolhidas pelos profissionais envolvidos no cuidado (GALVÃO MCB e DAVIM RMB, 2013; MATOS KKC, et al., 2018).

A assistência no período gravídico-puerperal foi insatisfatória e a literatura concorda com a descrição de um pré-natal falho e pouco eficiente. As mulheres relatam não receber orientações sobre parto, amamentação e cuidados com o recém-nascido, recebendo auxilio de colegas que possuem experiência com bebês (MILITÃO LP e KRUNO RB, 2014).

A média de consultas são duas por gestante, realizadas na unidade prisional, contribuindo para o déficit na vigilância da saúde materno-infantil (GALVÃO MCB e DAVIM RMB, 2013; MATOS KKC, et al., 2018). O atraso inicial do pré-natal e a baixa qualidade assistencial causam insegurança, insatisfação e medo. Gestantes apontam falta de disponibilidade médica para o atendimento e de medicação analgésica (PÍCOLI RP, et al., 2014; LEAL MC, et al., 2016; SANTANA AT, et al., 2016).

Segundo a Organização Mundial da Saúde (OMS) as duas consultas durante toda a gestação estão aquém do preconizado já que o número ideal de consultas é igual ou maior que seis (OMS, 1996). Devem iniciar antes da $12^{\mathrm{a}}$ semana, e necessitam da articulação entre os sistemas prisional e de saúde para garantir assistência e planejamento adequados para um pré-natal de qualidade (BRASIL, 2011; MINISTÉRIO DA SAÚDE, 2013; MINISTÉRIO DA SAÚDE, 2014; MINISTÉRIO DA SAÚDE, 2015).

As consultas são feitas de maneira rápida e objetiva, com aferição de dados antropométricos, altura uterina e batimento cardíaco-fetal. Orientações referentes à gestação, parto e pós-parto são omitidas, tornando o atendimento desumano e desatento (SANTANA AT, et al., 2016; FERREIRA LS, et al., 2017; MATOS KKC, et al., 2018).

A literatura reforça que o pré-natal é o momento para acompanhar a gestação, identificar intercorrências e intervir, evitando riscos à mãe e ao bebê, observar aspectos psicossociais e realizar ações preventivas, com informações qualificadas sobre este período (BRASIL, 2011; MINISTÉRIO DA SAÚDE, 2013; MINISTÉRIO DA SAÚDE, 2014; MINISTÉRIO DA SAÚDE, 2015).

Raramente a atuação dos profissionais de enfermagem é vista como positiva, sendo mencionado como o único profissional que realiza o acompanhamento do pré-natal dentro da instituição prisional, acompanhando alterações, intervindo precocemente, tratando, garantindo vacinação, disponibilizando exames e medicamentos (FERREIRA LS, et al., 2017).

Em contrapartida, algumas mulheres relatam falta de atuação direta e proativa do enfermeiro no pré-natal, sendo mencionadas consultas com a médica e medicação com a técnica de enfermagem (SANTANA AT, et al., 2016).

\section{O parto e puerpério da mulher privada de liberdade}

Há falta de estrutura, gestantes entrevistadas queixam da demora no encaminhamento à maternidade, fator que gera risco de nascimentos em locais impróprios, como nas celas ou no caminho do hospital. O meio de transporte mais utilizado para encaminhar as gestantes no momento do parto é a ambulância, seguido da viatura policial. As mulheres destacam o despreparo dos agentes penitenciários envolvidos no transporte (LEAL MC, et al., 2016; MATOS KKC, et al., 2018; MATOS KKC, et al., 2019; SILVA JB, et al., 2020). 
As gestantes e parturientes apresentam medos e dúvidas sobre o processo de parto em cárcere, indagam a respeito do local de nascimento, o tratamento recebido e o contato com o recém-nascido. As experiências mostram despreparo da equipe na atenção à saúde materno-infantil, perpassando o transporte para a maternidade e a comunicação à família. Há ausência de investimentos do Estado, negligência e omissão (MILITÃO LP e KRUNO RB, 2014; MAIA JS, et al., 2021).

A comunicação entre o sistema carcerário e a família da detenta é precária: há casos em que os familiares não são informados do início do trabalho de parto e, quando avisados, não conseguem chegar a tempo para acompanhar a mulher. A escolta policial não efetiva o contato com a família e são escassas as visitas que essas mulheres recebem, ainda na maternidade (LEAL MC, et al., 2016; MATOS KKC, et al., 2018; MATOS KKC, et al., 2019; SILVA JB, et al., 2020).

Um fator que dificulta as visitas de familiares na maternidade é a não realização de um cadastro prévio, via estabelecimento prisional, ocasionando não autorização para visitações à essa mulher (LEAL MC, et al., 2016; MATOS KKC, et al., 2018; MATOS KKC, et al., 2019; SILVA JB, et al., 2020). A falta da família nesse momento especial causa sensação de abandono e revolta contra o sistema carcerário e de saúde. Em geral, a família só consegue visitar a gestante e o bebê quando os mesmos retornam à penitenciária (SILVA JB, et al., 2020).

Documentos do governo ressaltam que a presença do acompanhante durante o pré-parto, parto e pósparto imediato é um direito, sendo de escolha da parturiente e deverá ser previamente cadastrado no estabelecimento prisional para poder acessar a maternidade. Tal norma gera desencontros no momento do parto e nas visitas à maternidade (MINISTÉRIO DA SAÚDE, 2014; MINISTÉRIO DA SAÚDE, 2015).

Sobre a atuação dos profissionais envolvidos no momento do atendimento, mulheres destacaram a violência, principalmente na forma verbal e psicológica. Além dos procedimentos invasivos, agressão física e negligência, falta humanização e orientação durante $o$ atendimento. Há relatos do uso de algemas durante 0 parto e a internação (LEAL MC, et al., 2016; MATOS KKC, et al., 2019; SILVA JB, et al., 2020). Destaca-se que poucas gestantes apontam o atendimento da equipe de saúde e agentes penitenciários como excelente, sentindo-se respeitadas quanto à sua intimidade (LEAL MC, et al., 2016).

Estudos, por meio de relatos, mostram que o trabalho de parto possui violência física, psicológica e obstétrica, onde desrespeitam as escolhas das mulheres e realizam procedimentos invasivos sem consentimento. Com isso, o acesso dessas mulheres às informações sobre seus direitos, baseados em evidências científicas, é necessário. Os profissionais atuantes devem ser capacitados, acolhendo as gestantes e estabelecendo uma relação de confiança, reduzindo os impactos e atuando na qualidade de vida (MINISTÉRIO DA SAÚDE, 2015; MINISTÉRIO DA SAÚDE, 2017; SALES AC, et al., 2021). A literatura ressalta que a utilização das algemas ou qualquer forma de contenção, tanto no transporte, quanto no trabalho de parto e internação, é proibida, sendo assegurada às mulheres pelo Conselho Nacional de Política Criminal e Penitenciária (MINISTÉRIO DA SAÚDE, 2014; MINISTÉRIO DA SAÚDE, 2015)

O puerpério imediato vivenciado pelas mães é pouco abordado nos estudos, a atenção é direcionada aos recém-nascidos e sua relação com a mãe, porém os estudos encontrados relatam um baixo número de consultas puerperais, contribuindo para a falta de orientação sobre o período pós-parto, riscos de infecções e cuidados com a ferida operatória (FERREIRA LS, et al., 2017; MATOS KKC, et al., 2018).

Sabe-se que o puerpério é um momento ideal para a transmissão de orientações, principalmente no que se refere ao planejamento reprodutivo por meio de ações preventivas e educativas, de acordo com a Lei №9.263 o SUS deve prover serviços de assistência à concepção e contracepção, atendimento pré-natal, assistência ao parto, ao puerpério e ao neonato, controle das doenças sexualmente transmissíveis, controle e prevenção dos cânceres cérvico-uterino e de mama (BRASIL, 1996).

As mulheres relatam que não foram orientadas sobre os cuidados com mamas no aleitamento materno, recém-nascido, atividades sexuais e métodos contraceptivos no pós-puerpério. Parte das mulheres desconhecem a distribuição de preservativo na visita íntima (PÍCOLI RP, et al., 2014). 
O escasso acompanhamento das puérperas e seus bebês reforça as dificuldades na amamentação e nos sentimentos de solidão e desamparo vivenciados pelas mulheres. Muitas afirmam que o abandono familiar é a experiência que mais as aflige. Estudos destacam que o puerpério tem o foco na criança, reduzindo os cuidados maternos (FLORES NMP e SMEHA LN, 2018; MAIA JS, et al., 2021).

\section{Formação de vínculo da mulher privada de liberdade com seu filho no ambiente prisional}

Muitas mulheres ficam felizes e positivas em relação a gravidez, mas percebem um pessimismo diante da situação complexa com as crianças em um ambiente desafiador (MATÃO MEL, et al., 2016; DIUANA V, et al., 2017; FOCHI MCS, et al., 2017; MATOS KKC, et al., 2018; SILVA JB, et al., 2020). O ambiente carcerário não é o ideal para o desenvolvimento de um recém-nascido, a adequação do ambiente para receber essas mulheres e seus conceptos, torna-se necessária (PíCOLI RP, et al., 2014).

A Lei № 13.257 implementa políticas públicas para a primeira infância (seis primeiros anos completos ou 72 meses de vida da criança), tais como a garantia que a gestante e a mulher com filho na primeira infância, em unidade de privação de liberdade, tenham ambiência, dentro das normas sanitárias e assistenciais do SUS para o acolhimento do filho, em articulação com o sistema de ensino competente, para desenvolvimento integral da criança, visto que a educação sequer foi mencionada pelas mulheres (BRASIL, 2016).

As gestantes relatam amor pelo filho e esse laço se intensifica com o nascimento e o convívio. O contato com 0 filho na prisão torna 0 isolamento e a solidão mais suportáveis, contudo, essas mulheres têm consciência que o ambiente carcerário não é adequado pois não atende as necessidades infantis, como lazer, recreação e atividades que estimulem o desenvolvimento cognitivo. Há falta de privacidade e tranquilidade devido a lotação nas celas e no pátio, há atrito entre as detentas e agentes penitenciários. As opiniões das mulheres fragmentam-se entre fortalecer o vínculo com o filho ou permitir seu contato com o mundo exterior, apesar do medo de perder a guarda da criança (MATÃO MEL, et al., 2016; DIUANA V, et al., 2017; FOCHI MCS, et al., 2017).

Há mulheres que optam por amamentar seus filhos o maior tempo possível, para assim mantê-los por perto. Mas há outras que interrompem o aleitamento materno antes do previsto, pois imaginam que assim a criança sentirá menos a separação (DIUANA V, et al., 2017).

A amamentação no ambiente prisional é conflituosa, muitas mulheres gostam da experiência e fortalecem o vínculo com o filho, enquanto outras, imaginam a separação e o sofrimento da criança. Questões fisiológicas, biológicas e sociais interferem no aleitamento, as mães percebem que a produção de leite está relacionada ao seu estado emocional e que o estresse dificulta ainda mais o processo (MAIA JS, et al., 2021).

Um ambiente inadequado e mal adaptado, também interfere na amamentação, apesar da Lei №11.942 garantir que os ambientes penais destinados às puérperas e seus filhos possuam berçário, espaço adequado para o cuidado das crianças e amamentação até os seis meses (MINISTÉRIO DA SAÚDE, 2014; MINISTÉRIO DA SAÚDE, 2015; MAIA JS, et al., 2021).

O Projeto de Lei 3644 prevê a substituição, a critério do juiz, da prisão preventiva pela prisão domiciliar para mães que amamentam, com exceções para casos de crime hediondo ou equiparado, como o tráfico de drogas, ou crime contra o próprio filho, fato que favorece o aleitamento, visto que este promove vínculo e deve ser estimulado, conforme Estatuto da Criança e do Adolescente (BRASIL, 2019). O acesso à saúde pública é garantido para mulheres e crianças nascidas em cárcere, assim como o acompanhamento por profissionais durante o puerpério e puericultura, prevenindo agravos e danos (MINISTÉRIO DA SAÚDE, 2014; MINISTÉRIO DA SAÚDE, 2015; MAIA JS, et al., 2021).

A vinculação intensa e exclusiva entre mãe e recém-nascido têm consequências: as crianças ficam dependentes das mães que, sozinhas enquanto cuidadoras, experimentam diversos sentimentos relacionados à maternidade, como a sensação de fracasso, arrependimento pelo encarceramento com o filho, cansaço e estresse pela condição de nutriz em tempo integral (DIUANA V, et al., 2017; MATOS KKC, et al., 2018). 


\section{Mulheres no sistema prisional: relações com a família e os profissionais}

Em relação à família, as visitas são pouco frequentes e mais realizadas pelos avós das crianças. A visita do pai costuma ser menos frequente devido encarceramento concomitante. A família afasta-se do cuidado pela distância entre a penitenciária e a cidade de origem da mulher, pelo cuidado com outros filhos, pela falta de estrutura do sistema prisional ou por causa da falta de postura e preconceito de alguns profissionais do sistema (LEAL MC, et al., 2016; MATOS KKC, et al., 2018).

Muitas mulheres já eram mães antes do encarceramento e mostram-se fragilizadas com o rompimento dos laços afetivos, acentuados pelo isolamento e pela ruptura com o meio social (FÉLIX RS, et al., 2017; FOCHI MCS, et al., 2017).

A relação das mulheres com profissionais de saúde e com agentes penitenciários é cheia de dualidades e evidencia-se o desequilíbrio de poder devido as regras institucionais que restringem o ato maternal (GALVÃO MCB e DAVIM RMB, 2013).

Ocorrem conflitos entre as detentas ou entre detentas e administração, motivados pelas normas da rotina prisional. As mães temem a separação de seus filhos e assim, a administração penitenciária modela e controla os comportamentos maternos. Os fatores que promovem atritos têm relação à alimentação, acesso dos recém-nascidos ao sistema de saúde, horários que restringem a liberdade das crianças, escassez de produtos para os filhos, como fraldas, roupas, itens de lazer e de higiene pessoal. Por fim, há falta de comunicação entre a administração, as mães e os familiares. As mulheres questionam a falta de humanização dos profissionais do cárcere, revelando baixa qualidade nessas relações (GALVÃO MCB e DAVIM RMB, 2013; SANTANA AT, et al., 2016; DIUANA V, et al., 2017; FERREIRA LS, et al., 2017; SOUZA GC, et al., 2018).

Sobre a separação forçada do binômio mãe-filho, situação traumática e violenta, seria menos conflituosa com o auxílio da família, quando essa pode abrigar a criança até o final da pena da mãe. Todavia, a falta de comunicação entre a administração carcerária e os familiares, somado às dificuldades para a visitação, acabam por piorar os laços e vínculos dessas mulheres com o meio exterior. Em situações onde não há familiares para receber a criança, impõe-se o encaminhamento do filho para um abrigo, fato pouco aceito pelas mães (DIUANA V, et al., 2017; ANDRADE ABCA e GONÇALVES MJF, 2018).

O preconceito permeia as relações dessas mulheres, são mencionados o público geral, profissionais do sistema prisional e de saúde, os quais julgam a gravidez por gerar "benefícios", como a transferência para presidio com acomodações melhores (LEAL MC, et al., 2016; DIUANA V, et al., 2017; SOUZA GC, et al., 2018).

Entre os profissionais, há poucos que tentam suprir as deficiências que ocorrem rotineiramente dentro do sistema carcerário, com empatia às mulheres, preocupando-se com o desenvolvimento físico, psicológico e social da criança (LOPES TC e PINHEIRO R, 2016; MATÃO MEL, et al., 2016; SILVA JB, et al., 2020).

\section{CONSIDERAÇÕES FINAIS}

As percepções das mulheres sobre o atendimento recebido durante o período gravídico-puerperal revelam fragilidades na assistência materno-infantil nas penitenciárias, as quais impactam diretamente na vida dos envolvidos. Houve relatos de direitos cerceados, pré-natal incompleto, ambiente inadequado para as necessidades do binômio mãe-filho, falta de comunicação entre o sistema e a família das mulheres e conflitos com os profissionais. A maioria das instituições necessita de adaptações para cumprir o que é preconizado, especialmente porque as penitenciárias brasileiras não estão organizadas para acolher as gestantes e seus filhos. Ainda prevalece o cunho de punição e opressão, evidenciados pelo preconceito da sociedade e dos profissionais atuantes e pela falta de um ambiente digno e bem estruturado. Alguns aspectos encontrados nos resultados não puderam ser discutidos com profundidade, devido à falta de literatura específica.

\section{REFERÊNCIAS}

1. ANDRADE ABCA, GONÇALVES MJF. Maternidade em Regime Prisional: Desfechos Maternos e Neonatais. Revista de Enfermagem Universidade Federal de Pernambuco Online, 2018; 12(6); 1763-1771.

2. ARAÚJO ANV, et al. Percepção de Mães Presidiárias sobre os Motivos que Dificultam a Vivência do Binômio. Revista de Enfermagem Contemporânea, 2014; 3(2);131-142. 
3. BRASIL. Presidência da República. Lei № 9.263, de 12 de janeiro de 1996.1996. Disponível em: http://www.planalto.gov.br/ccivil_03/leis/19263.htm. Acessado em: 10 de jul. de 2021.

4. BRASIL. Portaria no 1.459, de 24 de junho de 2011. 2011. Disponível em: https://bvsms.saude.gov.br/bvs/saudelegis/gm/2011/prt1459_24_06_2011.html. Acessado em: 15 de jun. de 2021.

5. BRASIL. Presidência da República. Lei № 13.257, de 8 de março de 2016. 2016. Disponível em: http://www.planalto.gov.br/ccivil_03/_ato2015-2018/2016/lei//13257.htm. Acessado em: 10 de jul. de 2021.

6. BRASIL. Presidência da República. Projeto de Lei № 3644/19, de 18 de junho de 2019 . Disponível em: https://www.camara.leg.br/proposicoesWeb/fichadetramitacao?idProposicao=2208697. Acessado em: 10 de jul. de 2021.

7. CONSELHO NACIONAL DE JUSTIÇA (CNJ). Sistema Prisional, Quantitativo Total de Gestantes e Lactantes por Mês. 2021. Disponível em: https://paineisanalytics.cnj.jus.br/single/?appid=f63a2001-ec5f-4d71-b81c-49e46f95e6f3\&sheet=6fff7a894517-47d8-91b2-9f905c57b58f\&lang=pt-BR\&opt=currsel\&select=NUM_ANO_MES_REF,43983. Acessado em: 15 de jun. de 2021.

8. DIUANA V, et al. Mulheres nas Prisões Brasileiras: Tensões entre a Ordem Disciplinar Punitiva e as Prescrições da Maternidade. Revista de Saúde Coletiva, 2017; 27(3); 727-747.

9. FÉLIX RS, et al. O Enfermeiro na Atenção Pré-Natal às Mulheres em Sistema Carcerário. Revista de Enfermagem Universidade Federal de Pernambuco Online, 2017; 11(10); 3936-3947.

10. FERREIRA LS, et al. Percepção de Presidiárias sobre a Assistência à Saúde Materna em uma Penitenciária Feminina. Revista Cubana de Enfermagem, 2017; 33(4);776-792.

11. FLORES NMP, SMEHA LN. Mães presas, filhos desamparados: maternidade e relações interpessoais na prisão. Physis: Revista de Saúde Coletiva, 2018; 28(4); 1-20.

12. FOCHI MCS, et al. Vivências de Gestantes em Situação de Prisão. Revista Eletrônica de Enfermagem, 2017 ; 19 ; a57.

13. FOCHI MCS, et al. Pré-natal em unidade básica de saúde a gestantes em situação prisional. Revista Rene Journal, 2014; 15(2); 371-377.

14. FRANÇA AMB, SILVA JMO. Maternidade em Situação de Prisão. Revista Baiana de Enfermagem, 2015; 29(4);411-420.

15. GALVẨO MCB, DAVIM RMB. Ausência de assistência à gestante em situação de cárcere penitenciário. Cogitare Enfermagem, 2013; 18(3); 452-459.

16. LEAL MC, et al. Nascer na prisão: Gestação e Parto atrás das Grades no Brasil. Revista Ciência \& Saúde Coletiva, 2016; $21(7) ; 2061-2070$.

17. LOPES TC, PINHEIRO R. Trajetórias de Mulheres Privadas de Liberdade: Práticas de Cuidado no Reconhecimento do Direito à Saúde no Centro de Referência de Gestantes de Minas Gerais. Revista de Saúde Coletiva, 2016; 26(4); $1193-1212$.

18. MAIA JS, et al. A percepção do puerpério atrás das grades. Global Academic Nursing Journal, 2021; 2(1); e69.

19. MATÃO MEL, et al. Maternidade Atrás das Grades: Particularidades do Binômio Mãe e Filho. Revista de Enfermagem do Centro Oeste Mineiro (RECOM), 2016; 6(2); 2235-2246.

20. MATOS KKC, et al. Representações de Mulheres Encarceradas sobre Gestar na Prisão. Revista de Enfermagem UFPE Online, 2018; 12(11); 3069-3077.

21. MATOS KKC, et al. Filhos do cárcere: representações sociais de mulheres sobre parir na prisão. Interface, $2019 ; 23: \mathrm{e} 180028$.

22. MILITÃO LP, KRUNO RB. Vivendo a gestação dentro de um sistema prisional. Saúde (Santa Maria), 2014; 40(1); 75-84.

23. MINISTÉRIO DA SAÚDE. Plano Nacional de Saúde no Sistema Penitenciário. 2004. Disponível em: http://bvsms.saude.gov.br/bvs/publicacoes/cartilha_pnssp.pdf. Acessado em: 17 de jan. de 2021.

24. MINISTÉRIO DA SAÚDE. Atenção ao pré-natal de baixo risco - Cadernos de Atenção Básica, $n^{\circ} 321^{\text {à }}$ edição revista. 2013. Disponível em: http://www.as.saude.ms.gov.br/wp-content/uploads/2016/07/Aten\%C3\%A7\%C3\%A30-ao-Pr\%C3\%A9-natalde-Baixo-Risco.pdf. Acessado em: 15 de jun. de 2021.

25. MINISTÉRIO DA SAÚDE. Inclusão das Mulheres em Privação de Liberdade na Rede Cegonha. 2014. Disponível em: http://189.28.128.100/dab/docs/portaldab/publicacoes/inclusao_mulheres_privacao_liberdade_rede_cegonha.pdf. Acessado em: 15 de jun. de 2021.

26. MINISTÉRIO DA SAÚDE. Atenção à saúde da mulher privada de liberdade. 2015 . Disponível em: https://ares.unasus.gov.br/acervo/html/ARES/7427/1/Saude_Mulher.pdf. Acessado em: 15 de jun. de 2021

27. MINISTÉRIO DA SAÚDE. Diretrizes nacionais de assistência ao parto normal. 2017. Disponível em: https://bvsms.saude.gov.br/bvs/publicacoes/diretrizes_nacionais_assistencia_parto_normal.pdf. Acessado em: 15 de jun. de 2021.

28. ORGANIZAÇÃO MUNDIAL DA SAÚDE (OMS). Boas práticas de atenção ao parto e ao nascimento. 1996. Disponível em: http://www.as.saude.ms.gov.br/wp-content/uploads/2016/07/Boas-Pr\%C3\%A1ticas-ao-Parto-e-Nascimento-1.pdf. Acessado em: 15 de jun. de 2021.

29. PÍCOLI RP, et al. Gestação e puerpério no cárcere: estudo descritivo da atenção à saúde. Revista Baiana de Saúde Pública, $2014 ; 38(1) ; 67-82$.

30. SALES AC, et al. Cuidado em saúde das mulheres grávidas privadas de liberdade: revisão integrativa. Revista Baiana de Enfermagem, 2021; 35:e36114.

31. SANTANA AT, et al. Mães do Cárcere: Vivências de Gestantes frente à Assistência no Pré-Natal. Revista Baiana de Saúde Pública, 2016; 40(1); 38-54.

32. SILVA JB, et al. Mulheres em Privação de Liberdade: Narrativas de Des(assistência) obstétrica. Revista Mineira de Enfermagem (REME), 2020; 24:e1346.

33. SISTEMA DE INFORMAÇÃO DE DEPARTAMENTO PENITENCIÁRIO NACIONAL (SISDEPEN). Aprisionamento feminino, período de janeiro a junho de 2020.2020. Disponível em: https://app.powerbi.com/view?r=eyJrljoiYzg4NTRjNzYtZDcxZi00ZTNkLWI1M2YtZGIzNzk3ODg0OTIIliwidCI6ImViMDkwNDI wLTQONGMtNDNmNy05MWYyLTRiOGRhNmJmZThIMSJ9. Acessado em: 9 de jul. de 2021.

34. SOUZA GC, et al. Reflexões sobre a assistência em enfermagem à mulher encarcerada: um estudo de revisão integrativa. Arquivo de Ciências da Saúde UNIPAR, 2018; 22(1); 55-62.

35. VENTURA $M$, et al. Maternidade atrás das grades: em busca da cidadania e da saúde. Um estudo sobre a legislação brasileira. Caderneta de Saúde Pública, 2015; 31(3); 607-619. 